\title{
How Green Lifestyle as Moderator Variable has Influenced Green Human Resource Management (GRHM) and Job Performance?
}

\author{
Wiwik Robiatul Adawiyah ${ }^{1}$, I Nyoman Putrawan ${ }^{2}$ \\ ${ }^{1,2}$ Department of Management, Faculty of Economy and Business, Trisakti University, Jakarta, Indonesia \\ Corresponding Author: Wiwik Robiatul Adawiyah
}

\begin{abstract}
The purpose of this study is to test the influence of green lifestyle as a variable moderator on GRHM and job performance. Green lifestyle is so less applied in the work environment by employees in some companies. Not all companies enforce discipline in applying a green lifestyle, while green lifestyle and GRHM can also bring influence to employee job performance. This research applied a quantitative approach with the regression method. The samples in this study were employees aged between 18-40 years. The samples studied were people of productive age. The data analysis technique used was regression using SPSS application. The results show that the green lifestyle does not affect GRHM on job performance directly. Green lifestyle affects job performance, while GRHM has a significant influence on green lifestyle and job performance.
\end{abstract}

Keywords: Green Lifestyle, Green Human

Resource Management (GRHM), Job

Performance

\section{INTRODUCTION}

Green lifestyle is one of the cultures that must be applied in the work environment. Green lifestyle has an important component that becomes the criteria in its application. A work environment where employees do not implement a green lifestyle will have an adverse impact in the long run. It can result in the disposal of production waste in a company that is not controlled, so it adversely affects the company's surrounding environment.

Not only green lifestyle is needed in a company to reduce the allocation of production waste, but also other aspects support it. Suppose a worker's behavior can be ascertained to apply a work culture that is friendly with the environment. In that case, the work environment's quality and the company will also be good (Joong, Gon, Choi, \& Phetvaroon, 2019). Culture in the work environment is related to the green lifestyle applied by employees of a company itself.

Green lifestyle is also related to Green Human Resource Management (GRHM). It is related to the rules and discipline applied by the company to its employees. If employees' arrangement and organization are also good, then the quality of employee performance will also be good. The quality of employee performance is related to job performance.

The impact of a company's production process can cause complex problems for the surrounding environment. This impact can be felt not only by workers within the company but also by the community around the company. One of the impacts of the company's production process is the production waste that causes global warming. Global warming has a very poor effect on the environment, both shortterm and long-term effects.

Global warming itself can be reduced by reducing the behavior of 
employees who do not maintain environmental health. Some companies have already paid attention to the adverse effects of global warming that can occur in any region that could affect a region's economy. To reduce the effects of global warming, some companies apply habituation to employees to do "Go Green" or do a lifestyle that pays attention to greening the environment or called a green lifestyle.

Green habituation lifestyle is familiar among many circles. This habituation can be done by changing the habits of employees who pay less attention to the surrounding environment than small things, including in considering the disposal of production waste. This requires special control of the Human Resources section in a company that cooperates with other parts to pay attention to each employee group. Employees' behavior that aims to maintain the environment today can also change the habits in work or everyday life, starting with changing behaviors and mindsets. It can be called an effort to save the earth and the environment from global warming.

The increasing population is a factor of environmental damage with various impacts, such as decreased quantity and quality, abandoned housing and land settlements, loss of green open space function, and more day development carried out by big cities. There is also an invitation made by the government always to do water saving which means keeping the earth. Efforts that can be made by the company to save the environment by switching with an environmentally friendly lifestyle at work.

The mention of "Go Green" is familiar to the people in the world. This "Go Green" appears to save the environment from global warming as proclaimed by the United Nations scientists team (IPCC), namely that humans are the main source of global warming itself. Therefore, human beings are the main pillars to preserve and conserve the environment. Ethical awareness about the environment makes the company have an environmentally friendly concept (Green Company) and has now become a necessity in the business era in the post-modern era as it is today. The company's goal, which is used to make the most profit by minimizing production costs, has now found that savings must start from within the company's stakeholders (Manolas, Tsantopoulos, \& Dimoudi, 2017).

The achievements of Human Resource Management (HRM) today focus on saving the environment and social ethics to preserve it, and this has been discussed in recent decades about the concept of Green Human Resource Management (GHRM), which gets special attention from the world (Joong, Gon, Choi, \& Phetvaroon, 2019). According to Ali, Islam. \& Parveen, (2017) Green Human Resource Management is crucial for companies to gain a competitive advantage, high-performance organizations, and success in organizing.

Environmentally friendly human resources are getting less and less. This is a real condition where individuals do not have the awareness to develop "go green" behavior or habituation to have a green lifestyle. This habituation requires providing insight into green behavior to all employees in each company. In this study, researchers identified the influence of green lifestyle (green behavior) and GRHM on employee performance in PT. Cabot Indonesia.

\section{MATERIALS \& METHODS}

The method used in this research was the method of influence with a quantitative approach. The research subjects were employees of PT. Cabot Indonesia with sampling techniques using nonprobability sampling through purposive sampling. The number of samplings in this study was 200 people. The consideration of sampling used in this study was a minimum sample number of 5 to 10 times all statement items in the research instrument used (Hair et al., 2010). If referring to the theory, if applied in the study with the number of items 30 statements, then the minimum number of samples is 185 people, as well as a maximum number of samples of 
370 people. These sample criteria are taken based on the age and length of work at PT. Cabot Indonesia.

The instruments used were GHRM, Green lifestyle, and Job Performance questionnaires that had high reliability and validity in each instrument. Researchers conducted data collection by distributing instruments to employees of PT. Cabot Indonesia. Data analysis used was SEM Analysis as a statistical application to test hypotheses for the influence of all three variables in this study. The related picture for the analysis of this research hypothesis was green lifestyle as a moderator variable capable of influencing GRHM and job performance as variables tied to the research paradigm's description as follows:

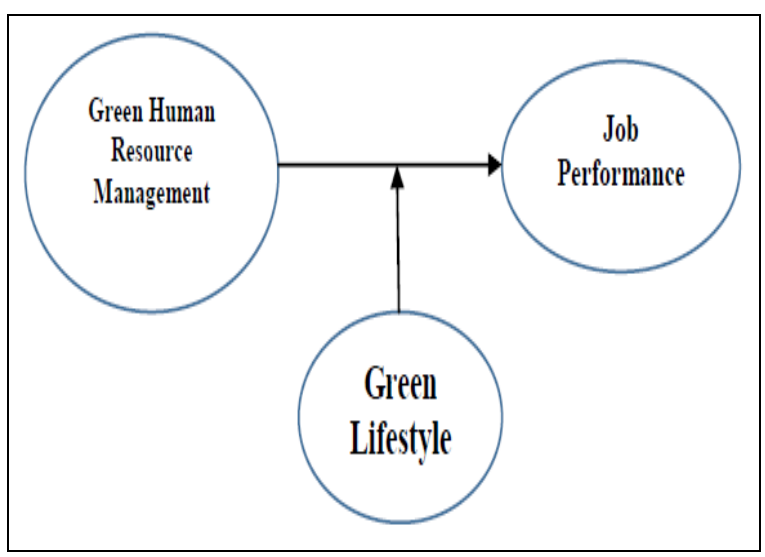

Figure 1: Research Paradigm

\section{RESULT AND DISCUSSION}

Table 1: Respondents Demographic Data by Age \begin{tabular}{|c|c|c|}
\hline Age (Year) & Freq. & Percentage $(\%)$ \\
\hline
\end{tabular}

\begin{tabular}{|c|c|c|}
\hline $20-30$ & 103 & 51.5 \\
\hline $31-40$ & 89 & 44.5 \\
\hline $41-50$ & 5 & 2.5 \\
\hline$>50$ & 3 & 1.5 \\
\hline Total & $\mathbf{2 0 0}$ & $\mathbf{1 0 0 , 0}$ \\
\hline
\end{tabular}

Source: Data Processing Results using Ms. Excel

This study's results reveal that the description of research subjects with categories based on age, length of employment of respondents, level of education, instrument feasibility test, and influence test of a green lifestyle, green human resource management with job performance in 200 employees of PT. Cabot Indonesia. Based on the results of the identification of subjects based on age, the following results were obtained for the age categorization of respondents who filled out questionnaires shared by researchers.

The table above shows that the respondents who filled out the three questionnaires were dominated by workers aged 20-30 years with a percentage of $51.5 \%$. The age of 20-30 years is considered the productive age to work in a company. Therefore, considering the workers of a company prioritizes workers whose age is considered still productive. The respondents' analysis was also supported by the length of work and the level of education in respondents who filled out questionnaires from researchers. Based on the results of descriptive statistical tests, the results of identifying the length of work and the level of education of respondents can be described as follows.

Table 2: Respondents' Length of Work Profile

\begin{tabular}{|c|c|c|}
\hline Length of Work & Frequency & Percentage (\%) \\
\hline <5 Year & 139 & 69.5 \\
\hline 5-10 Year & 51 & 25.5 \\
\hline 11-15 Year & 5 & 2.5 \\
\hline >15 Year & 5 & 2.5 \\
\hline Total & $\mathbf{2 0 0}$ & $\mathbf{1 0 0 . 0}$ \\
\hline
\end{tabular}

Source: Data Processing Results using Ms. Excel

The table above shows that the workers who filled out the dominant questionnaire had a length of employment at PT. Cabot Indonesia is less than 5 years old with a percentage of $69.5 \%$. While in the second place is a worker with a working duration of 5-10 years with a percentage of 25.5\%. This is because, in PT Cabot Indonesia, the majority rely on employees who are still relatively new to work at the company to provide new ideas or ideas to be able to overcome problems in work and provide solutions to existing problems. From workers who have an age range of 2030 years with a working duration of fewer than 5 years, individual work performance is categorized quite well. In addition, researchers identified the dominant workers of productive age who had the decision to work at PT. Cabot Indonesia, who has only worked less than 5 years, has the last education as follows. 
Wiwik Robiatul Adawiyah et.al. How green lifestyle as moderator variable has influenced Green Human Resource Management (GRHM) and job performance?

Table 3: Respondents' Last Education Profile

\begin{tabular}{|c|c|c|}
\hline Education Profile & Frequency & Percentage $(\%)$ \\
\hline Junior High School & 0 & 0 \\
\hline High School & 0 & 0 \\
\hline Diploma Degree & 4 & 2.0 \\
\hline Bachelor-Doctoral Degree & 196 & 98.0 \\
\hline Total & 200 & 100.0 \\
\hline
\end{tabular}

Source: Data Processing Results using Ms. Excel

From the data above, dominant pt workers. Cabot Indonesia has the last education S1-S3, which has a frequency of 196 people with 98\%. Employees who are respondents to this research mostly have an excellent educational background and are considered competent, and have extensive knowledge in working on their work responsibilities under the criteria of consideration of employee acceptance at PT. Cabot Indonesia. The three data descriptions in the form of respondents' demographic data, the length of work of respondents, and the last education of respondents are considered factors that influence job performance. To be more convincing, it is necessary to do some testing of other variables that become moderator variables in this study, namely the Green lifestyle and Green Human Resource Management (GHRM) Practice.

Before proceeding to hypothesis testing, it notices that the instruments used in this study have a fairly good measuring power against green lifestyle, Green Human Resource Management (GHRM) practice, and Job Performance mentioned as follows.

Table 4: The Instrument Quality
\begin{tabular}{|l|c|c|}
\hline \multicolumn{1}{|c|}{ Variable } & Validity & Reliability \\
\hline Green Lifestyle & Good & 0,835 \\
\hline GHRM & Good & 0,978 \\
\hline Job Performance & Good & 0,879 \\
\hline
\end{tabular}

The table above shows that all three questionnaires have good validity and high reliability. Furthermore, the three variables above were influence tested using SEM analysis using an AMOS application that generates the following data.

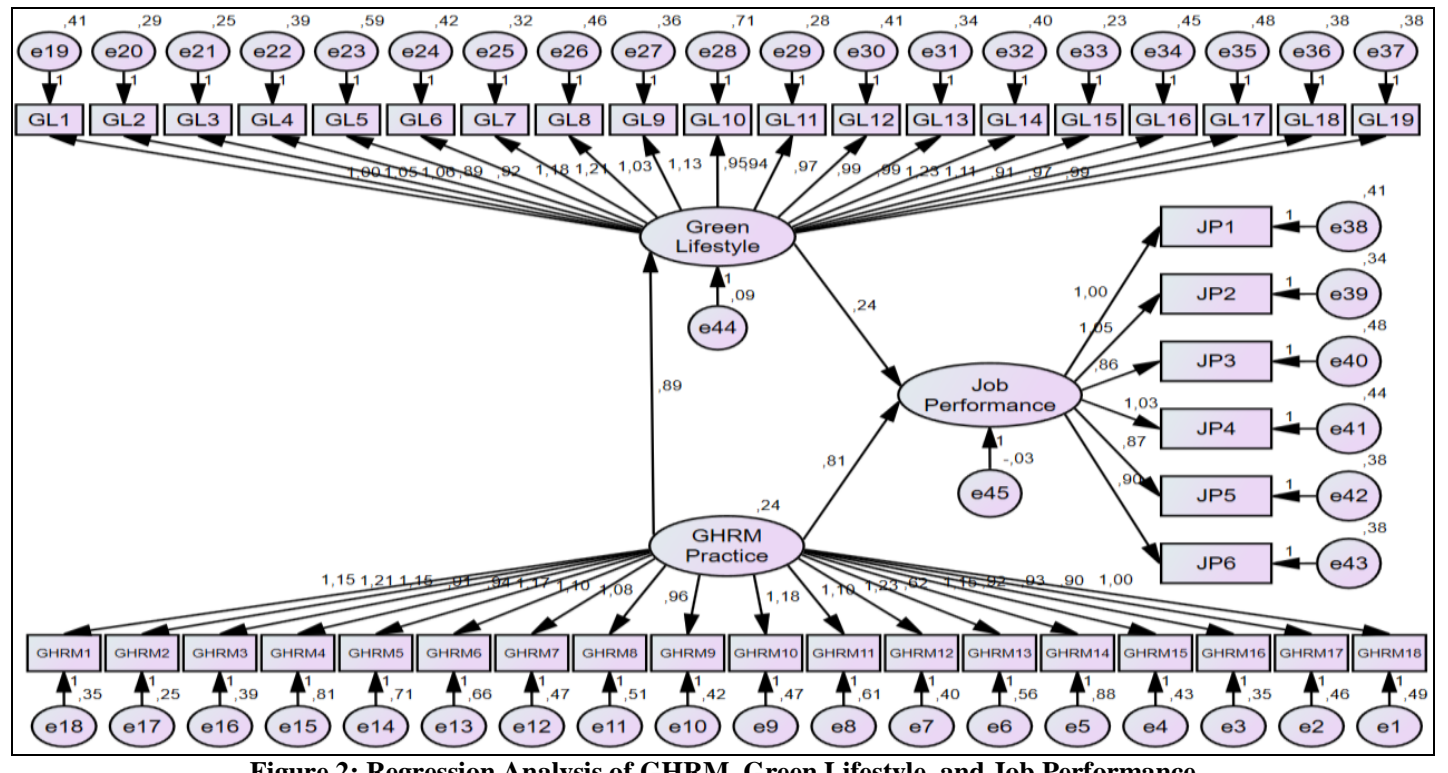

Figure 2; Regression Analysis of GHRM, Green Lifestyle, and Job Performance

The picture above shows that the green lifestyle has no effect on GRHM on direct job performance. However, the green lifestyle has a significant effect on job performance, as evidenced by the p-value of 0.000 . Then, GRHM has a significant influence on green lifestyle, and GRHM also significantly affects job performance with a p-value of 0.000 . Based on the results of the path analysis conducted above, it can be known in green lifestyle variables have 19 components that can be influenced by GRHM Practice, which has 18 components that make up the variables. Green lifestyle and GRHM Practice both variables are equally capable of influencing job performance variables with six components that make it up. In the analysis of the above lines, it can be concluded that GRHM practice can affect green lifestyle and job 
performance. While the green lifestyle can be influenced by GRHM practice and it can also affect job performance.

The above conclusion can be proven from the p-value of the regression test shown in the regression weight table based on the significant number of the p-value column. If the sign is less than 0.05 , then the hypothesis that has been concluded above can be declared acceptable. The hypothesis can be rewritten; namely, the green lifestyle is influenced by GRHM practice, and the green lifestyle and GRHM practice can influence job performance. The influence values between variables can be seen in column $\mathrm{p}$ values in the table below.

Tabel 5. Regression Weight

\begin{tabular}{|c|c|c|c|c|c|c|c|}
\hline & & & Estimate & S.E. & C.R. & $\mathbf{P}$ & Label \\
\hline Green_Lifestyle & $<--$ & GHRM_Practice &, 866 & ,136 & 6,379 & $* * *$ & \\
\hline Job_Performance & $<--$ & Green_Lifestyle & , 456 &, 083 & 5,499 & $* * *$ & \\
\hline Job_Performance & $\begin{array}{ll}<-- \\
\end{array}$ & GHRM_Practice &, 415 & ,092 & 4,512 & $* * *$ & \\
\hline GHRM18 & <--- & GHRM_Practice & 1,000 & & & & \\
\hline GHRM17 & $\begin{array}{l}<-- \\
\end{array}$ & GHRM_Practice &, 831 & , 118 & 7,066 & $* * *$ & \\
\hline GHRM16 & $\begin{array}{ll}<-- \\
\end{array}$ & GHRM_Practice & ,846 & 136 & 6,225 & $* * *$ & \\
\hline GHRM15 & $\begin{array}{l}<-- \\
\end{array}$ & GHRM_Practice &, 855 &, 144 & 5,934 & $* * *$ & \\
\hline GHRM14 & $\begin{array}{l}<-- \\
\end{array}$ & GHRM_Practice & 1,010 & , 196 & 5,158 & $* * *$ & \\
\hline GHRM13 & <--- & GHRM_Practice & ,602 &, 134 & 4,500 & $* * *$ & \\
\hline GHRM12 & $\begin{array}{ll}<-- \\
\end{array}$ & GHRM_Practice & 1,157 &, 154 & 7,502 & $* * *$ & \\
\hline GHRM11 & <--- & GHRM_Practice & 1,112 &, 173 & 6,412 & $* * *$ & \\
\hline GHRM10 & $\begin{array}{l}<-- \\
\end{array}$ & GHRM_Practice & 1,141 & 157 & 7,282 & $* * *$ & \\
\hline GHRM9 & $\begin{array}{ll}<-- \\
\end{array}$ & GHRM_Practice & ,900 & 146 & 6,162 & $* * *$ & \\
\hline GHRM8 & $\begin{array}{l}<-- \\
\end{array}$ & GHRM_Practice & ,939 &, 157 & 5,984 & $* * *$ & \\
\hline GHRM7 & <--- & GHRM_Practice & 1,007 & , 148 & 6,789 & $* * *$ & \\
\hline GHRM6 & $\begin{array}{l}<-- \\
\end{array}$ & GHRM_Practice & 1,066 &, 173 & 6,154 & $* * *$ & \\
\hline GHRM5 & $<--$ & GHRM_Practice & ,809 &, 164 & 4,940 & $* * *$ & \\
\hline GHRM4 & <--- & GHRM_Practice & ,798 & , 167 & 4,773 & $* * *$ & \\
\hline GHRM3 & $\begin{array}{ll}<-- \\
\end{array}$ & GHRM_Practice & 1,045 &, 153 & 6,828 & $* * *$ & \\
\hline GHRM2 & $\begin{array}{l}<-- \\
\end{array}$ & GHRM_Practice & 1,037 &, 141 & 7,334 & $* * *$ & \\
\hline GHRM1 & $<--$ & GHRM_Practice & ,967 &, 143 & 6,756 & $* * *$ & \\
\hline
\end{tabular}

The table above shows the results of research where the green lifestyle significantly affects job performance. At the same time, GRHM can affect the green lifestyle and hob performance significantly. This is because the green lifestyle cannot affect GRHM on job performance simultaneously. While work achievement can be influenced by the green lifestyle and GRHM as evidenced by the p-value of 0.000 which means both green lifestyle and GRHM have a significant influence.

The results of this study are supported by the results of previous research that shows that green knowledge has a negative impact on the green lifestyle in students who consume instant noodles, while green awareness can affect the green lifestyle positively but not significantly (Hudrasyah, 2013). The study tested the influence between green knowledge, green awareness on green impact behavior (green lifestyle), which showed three influential but insignificant variables indicated by significance figures of -0.014 and 0.028 .
The other research that supports the above research results is consumers who cultivated the green lifestyle to do some green attribute value to the low involvement of the use of products that are not environmentally friendly. They tended to apply intense attitudes and behaviors to the green lifestyle. This impacted companies that did not implement the green lifestyle, which also impacted the acceptance and demand of products from outside (Florenthal, 2011). The study that placed the green lifestyle as a moderator variable also produced data showing that the green lifestyle affected workers' work culture and job performance. Thus, it could have implications on employees' performance and lifestyle shown in the workplace environment, namely national and multinational companies in the area of the National Capital Region of Philippines (Fatima et al., 2017). 


\section{CONCLUSION}

The results of the research show that the green lifestyle cannot affect the correlation of Green Human Resource Management Practice (GHRM) and the job performance of PT employees Cabot Indonesia. The green lifestyle can affect job performance, while GRHM can affect the green lifestyle and job performance significantly. These results are supported by an estimated measurement value generated between GHRM and job performance that results in a value of 0.415 and for a green lifestyle of 0.456. Meanwhile, SEM analysis obtained the p-value that shows the p-value below 0.05 from the green lifestyle and GRHM to job performance.

\section{REFERENCES}

1. Ali Islam \& Parveen. (2017). The Impact of Human Resource. Management Practices, 38 (July), 26-32.

2. College, P. G. D. A. V. (2014). Green HRM-A Requirement for Sustainable Organization ABSTRACT, 1991-1992.

3. Fatima, S., Ragas, P., Mae, F., Tantay, A., Joyce, L., Chua, C., Tantay, A. (2017). Green lifestyle moderates GHRM's impact on job performance. https://doi.org/10.1108/ IJPPM-04-2016-0076

4. Florenthal, B. (2011). Do Green Lifestyle Consumers Appreciate Low Involvement Green Products?. Marketing Management Journal, 35-45.

5. Fogaça, N., Carolina, M., Rego, B., \& Cortat, M. (2018). Job Performance Analysis: Scientifi c Studies in the Main Psychology from 2006 to 2015, 0, 231-247. https://doi.org/10.1002/piq

6. Heir et al. (2010). Multivariate Data Analysis (7th Ed.) Pearson Prentice Hall: USA

7. Hudrasyah, H. (2013). The Green Knowledge and Green Awareness Influences Analysis on Green Behavior And Its Impact On Green Lifestyle Of Instant
Noodles Consumer (Case Study: Bandung Institute Of Technology'S Undergraduate Students), 2(19), 2250-2256.

8. Johari, J., Shamsudin, M. F., Adnan, Z. (2018). Job characteristics, employee wellbeing, and job performance of public sector employees in Malaysia. https://doi.org/10. 1108/IJPSM-09-2017-0257

9. Joong, Y., Gon, W., Choi, H., \& Phetvaroon, K. (2019). International Journal of Hospitality Management The effect of green human resource management on hotel employees' eco- friendly behavior and environmental performance. International Journal of Hospitality Management, 76 (April 2018), 83-93. https://doi.org/10. 1016/j.ijhm.2018.04.007

10. Manolas, E., Tsantopoulos G., Dimoudi, K. (2016). Management of Environmental Quality: An International Journal Article information: Energy saving and the use of "green" bank products: the views of the citizens. https://doi.org/10.1108/ MEQ-052016-0042

11. Nasr, L. (2019). Employee engagement and job performance in Lebanon: the mediating role of creativity. https://doi.org/10.1108/ IJPPM-02-2018-0052

12. Tang, G., Chen, Y., Jiang, Y., \& Jia, J. (2017). Green human resource management practices: scale development and validity, (555).https://doi.org/10.1111/1744-7941. 12147

13. Zimmerman, R. D., \& Darnold, T. C. (2007). The impact of job performance on employee turnover intentions and the voluntary turnover process A meta-analysis and path model, 1949. https://doi.org/10. 1108/00483480910931316

How to cite this article: Wiwik Robiatul Adawiyah, I Nyoman Putrawan. How green lifestyle as moderator variable has influenced Green Human Resource Management (GRHM) and job performance? International Journal of Research and Review. 2021; 8(2): 89-94. 